Please do not remove this page

RMIT

UNIVERSITY

\title{
Two-dimensional lubrication analysis and design optimization of a Scotch Yoke engine linear bearing
}

Wang, Xu; Subic, Aleksandar; Watson, Harry

https://researchrepository.rmit.edu.au/esploro/outputs/9921859724101341/filesAndLinks?institution=61RMIT_INST\&index=null

Wang, X., Subic, A., \& Watson, H. (2006). Two-dimensional lubrication analysis and design optimization of a Scotch Yoke engine linear bearing. Institution of Mechanical Engineers. Proceedings. Part C: Journal of Mechanical Engineering Science, 220(10), 1575-1587. https://doi.org/10.1243/0954406jmes260

Published Version: https://doi.org/10.1243/0954406jmes260

Repository homepage: https://researchrepository.rmit.edu.au

(c) Professional Engineering Publishing

Downloaded On 2023/04/26 22:50:10 +1000 


\title{
Two-dimensional lubrication analysis and design optimization of a Scotch Yoke engine linear bearing
}

\author{
X Wang $^{1 *}$, A Subic ${ }^{1}$, and $\mathbf{H}$ Watson $^{2}$ \\ ${ }^{1}$ School of Aerospace, Mechanical and Manufacturing Engineering, RMIT University, Melbourne, Australia \\ ${ }^{2}$ Department of Mechanical and Manufacturing Engineering, The University of Melbourne, Melbourne, Australia
}

The manuscript was received on 12 December 2005 and was accepted after revision for publication on 19 June 2006.

DOI: 10.1243/0954406JMES260

\begin{abstract}
Recent study has shown that the application of a Scotch Yoke crank mechanism to a reciprocating internal combustion engine reduces the engine's size and weight and generates sinusoidal piston motion that allows for complete balance of the engine.

This paper describes detailed investigation of the performance of a linear bearing assembly, which is one of the key components of the Scotch Yoke mechanism. The investigation starts by solving Reynolds equation for the Scotch Yoke linear bearing. The two-dimensional lubricant flow is numerically simulated and the calculated results are compared with experimental results from a linear bearing test rig. The performance characteristics and a design sensitivity analysis of the bearing are presented. Dynamic testing and analysis of an instrumented linear bearing on a test rig are used to validate the numerical simulation model. The oil supply and lubrication mechanism in the linear bearing are analysed and described in detail. This work aims to provide new insights into Scotch Yoke linear bearing design. In addition, strategies for optimization of the linear bearing are discussed.
\end{abstract}

Keywords: hydrodynamic lubrication, linear bearing, Scotch Yoke engine, engine friction, vehicle power system, internal combustion engine

\section{INTRODUCTION}

Patents on the Scotch Yoke crank mechanism date back to the last century $[\mathbf{1}-\mathbf{4}]$. This type of mechanism has been used primarily in reciprocating machinery, including water pumps and internal combustion engines. Recent research on the Scotch Yoke engine has mainly focused on the reduction of engine size and weight and on improvement of aspects of the engine performance including drivability and engine balance, as reported in references [1-3]. However, limited published information exists in relation to the lubrication mechanism of the Scotch Yoke linear bearing.

In a Scotch Yoke engine, pairs of opposed pistons are rigidly connected by very short connecting rods

\footnotetext{
${ }^{*}$ Corresponding author: School of Mechanical and Manufacturing Engineering, RMIT University, Building 251, Level 3, 264 Plenty Road, PO Box 71, Bundoora, Victoria 3083, Australia. email:xu.wang@rmit.edu.au
}

and four 'C' plates, which link the connecting rods, as shown in Fig. 1. The linear bearing surfaces are the opposed parallel guide surfaces built on the connecting rods transverse to the axes of the pistons. The bearing block contains the linear bearing and journal bearing shells, which run on a crankpin of the crankshaft. The lubrication performance of the linear bearing determines the effectiveness of the Scotch Yoke mechanism and influences the performance of a Scotch Yoke engine in areas such as fuel consumption, output power, and reliability.

This paper presents the results of experimental investigation, theoretical analysis, and numerical simulation of the Scotch Yoke linear bearing lubrication mechanism. In particular, the following three aspects are investigated in detail.

1. Solving the Reynolds equation for the linear bearing using a two-dimensional lubricant flow model and theoretical analysis of the behaviour of the 


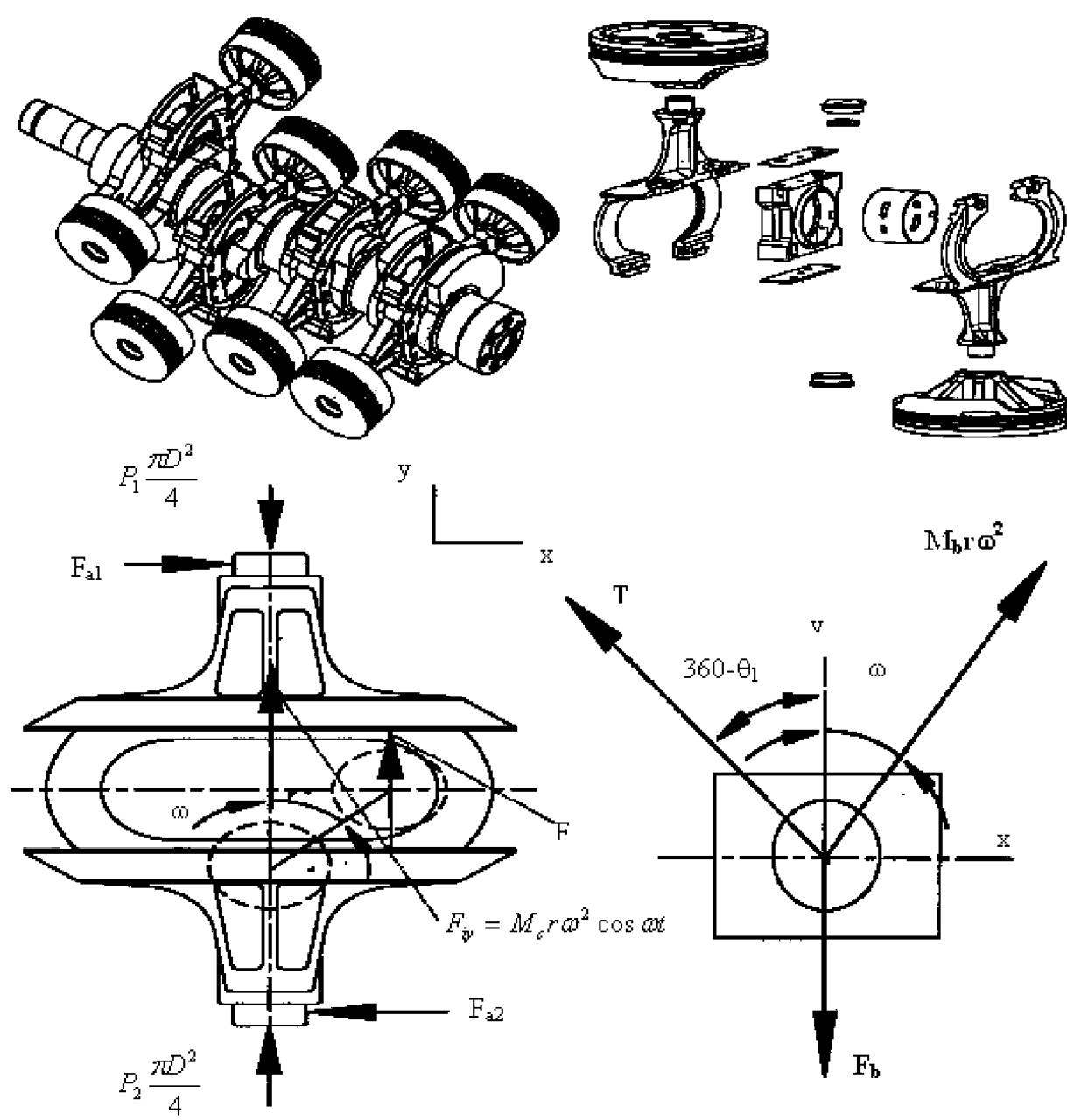

Fig. 1 Force resolution of the single piston-con-rod assembly in a CMC Scotch Yoke engine where pistons, connecting rods, and the linear bearing are presented [2]

bearing oil-film, considering both 'sliding' and 'squeezing' actions of the film.

2. Establishing a sliding velocity model of the linear bearing on a test rig and verifying lubrication modelling effectiveness of the test rig by comparing the linear bearing reaction forces in the test rig and in the CMC Scotch Yoke engine.

3. Analysing and discussing the simulation results and their applications.

The main purpose of this research was to solve the Reynolds equation for the oil-film pressure in the linear bearing as a two-dimensional lubricant flow problem and to compare analytical results with experimental ones. The theoretical model is applied to illustrate and explain the lubrication process in the linear bearing and to evaluate the lubrication performance of the linear bearing with respect to different geometrical design parameters, oil supply pressure, oil supply timing, and engine speeds.

\section{REYNOLDS EQUATION FOR A SCOTCH YOKE LINEAR BEARING}

The Scotch Yoke engine linear bearing block moving at a general crank angle position is shown in Fig. 1. In order to investigate the lubrication mechanism of the Scotch Yoke linear bearing, the relevant Reynolds equation for the linear bearing must be established and solved. The assumptions made in establishing the Reynolds equation are the following.

1. The bearing is completely filled with incompressible oil.

2. There are no spatial viscosity variations.

3. The linear bearing inclination angle is small because of the small clearance between the linear bearing block and the connecting-rod surfaces.

The simplified Reynolds equation for the linear bearing takes the form of a two-dimensional lubricant 
flow, as in reference [5]

$$
\frac{1}{6 \mu}\left[\frac{\partial}{\partial x}\left(h^{3} \frac{\partial p}{\partial x}\right)+\frac{\partial}{\partial z}\left(h^{3} \frac{\partial p}{\partial z}\right)\right]=2 V-\frac{\partial h}{\partial x} U
$$

where $V$ is the squeezing speed of the linear bearing block with respect to the connecting rod and $U$ is the sliding speed of the linear bearing block with respect to the connecting rod at a crank angle position as illustrated in Fig. 1; oil viscosity $\mu$ is evenly distributed and independent of $x$ and $z$; and $p$ is the oil-film pressure. The oil-film thickness $h$ is assumed constant in the $z$-direction and is a function of $x$ alone. It can be written as

$$
h(x)=\frac{h_{2}-h_{1}}{L} x+h_{1}
$$

where $h_{1}$ and $h_{2}$ are the oil-film thicknesses at the trailing and leading edges. $L$ is the length of the linear bearing and $x=0$ is at the thinner oil-film end $\left(h=h_{1}\right)$ of the bearing.

On the right-hand side (RHS) of equation (1), there are two terms: the first term representing 'squeezing hydrodynamic action' of the linear bearing and the second term representing 'sliding hydrodynamic action' of the linear bearing.

If only the 'squeezing hydrodynamic action' of the linear bearing is considered in equation (1), assuming that the sliding speed $U=0$ and that there is constant pressure distribution along the length of the linear bearing, i.e. $(\partial p / \partial x)=0$, then equation (1) becomes

$$
\frac{\partial}{\partial z}\left(h^{3} \frac{\partial p}{\partial z}\right)=12 \mu V
$$

For the boundary conditions at $z=\left(B_{\mathrm{w}} / 2\right),(\mathrm{d} p / \mathrm{d} z)=$ 0 and at $z=0$ or $z=B_{\mathrm{w}}, p=0$, integrating equation (3) twice and considering equation (2) for $h(x)$ gives

$$
p(x, z)=\frac{6 \mu V z}{\left(\left(h_{2}-h_{1} / L\right) x+h_{1}\right)^{3}}\left[z-B_{\mathrm{w}}\right]
$$

The bearing load capacity is, therefore, given by

$$
F=L \int_{0}^{B_{\mathrm{w}}} \frac{6 \mu V}{h^{3}}\left[z^{2}-z B_{\mathrm{w}}\right] \mathrm{d} z=-\frac{\mu V L B_{\mathrm{w}}^{3}}{h^{3}}
$$

It is seen from equations (4) and (5) that under the squeezing effect, as the squeezing velocity and the oil viscosity increase and as the oil-film thickness decreases, the oil-film pressure and the bearing load capacity increase. The load capacity is proportional to the cube of the bearing width and is proportional to the bearing length. The oil-film pressure and the bearing load capacity are inversely proportional to the cube of the oil-film thickness.

Similarly, if only the 'sliding hydrodynamic action' is considered in equation (1), assuming that the squeezing speed $V=0$ and ignoring the pressure variations across the bearing width, i.e. $\partial p / \partial z=0$, equation (1) becomes

$$
\frac{1}{6 \mu}\left[\frac{\partial}{\partial x}\left(h^{3} \frac{\partial p}{\partial x}\right)\right]=-\frac{\partial h}{\partial x} U
$$

By integrating equation (6) twice and considering equation (2) as well as the boundary conditions, at $x=0, h=h_{1}, p=0$, and at $x=L, h=h_{2}, p=0$, the following equation is obtained

$$
\begin{aligned}
p(x)= & \frac{6 \mu L U}{h_{2}-h_{1}}\left[\frac{1}{\left(\left(h_{2}-h_{1} / L\right) x+h_{1}\right)}\right. \\
& \left.-\frac{1}{\left(\left(h_{2}-h_{1} / L\right) x+h_{1}\right)^{2}} \frac{h_{1} h_{2}}{h_{1}+h_{2}}-\frac{1}{h_{1}+h_{2}}\right]
\end{aligned}
$$

It is seen from equation (7) that under the sliding effect, as the sliding velocity, the bearing length, and the oil viscosity increase, the oil-film pressure and the bearing load capacity increase. The oil-film pressure and the bearing load capacity are inversely proportional to the oil-film thickness and the inclination angle.

In the Scotch Yoke engine, both the squeezing and sliding effects of the linear bearing must be considered and, therefore, equation (1) will have to be solved for a two-dimensional lubricant flow as follows.

\section{NUMERICAL SOLUTION OF THE REYNOLDS EQUATION FOR A TWO-DIMENSIONAL LUBRICANT FLOW}

To analyse the two-dimensional lubricant flow, a finite-difference method is employed to obtain a numerical solution of the Reynolds equation. The finite difference mesh is formed for the bearing, and each inner node, where the pressure is not known, is assigned a node number. As shown in Fig. 2, the bearing surface is divided into 105 elements, i.e. the number of nodes is $8 \times 16=128$. The node $(i, j)$ represents the $i$ th count in the $x$-direction and the $j$ th count in the $z$-direction where the coordinate is $\left(x_{i, j}, z_{i, j}\right)$. The generalized subscripts are introduced to form the partial derivatives of $p$ and $h$ in equation (1) at the node $(i, j)$, using central differentiation as 

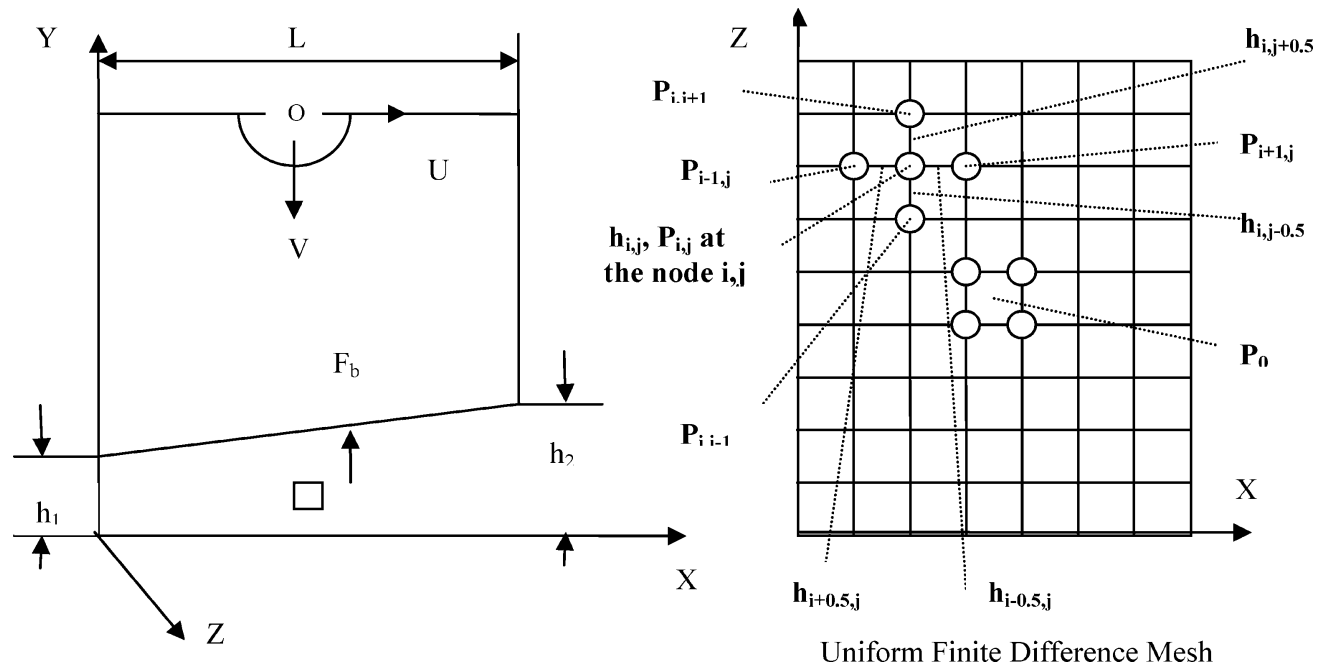

Fig. 2 Resolution of the linear bearing force for hydrodynamic lubrication at one instantaneous crank angle position and node numbering for uniform finite difference meshes

shown in Fig. 2. The following relationships are derived

$$
\begin{aligned}
& \frac{\partial}{\partial x}\left(h^{3} \frac{\partial p}{\partial x}\right)=\frac{h_{i+0.5, j}^{3}\left(p_{i+1, j}-p_{i, j} / \mathrm{D} x\right)}{-h_{i-0.5, j}^{3}\left(p_{i, j}-p_{i-1, j} / \mathrm{D} x\right)} \\
& \mathrm{D} x \\
& \frac{\partial}{\partial z}\left(h^{3} \frac{\partial p}{\partial z}\right)=\frac{-h_{i, j-0.5}^{3}\left(p_{i, j}-p_{i, j-1} / \mathrm{D} z\right)}{\mathrm{D} z} \\
& \frac{\partial h}{\partial x}=\frac{h_{i+0.5, j}-h_{i-0.5, j}}{\mathrm{D} x}
\end{aligned}
$$

where $\mathrm{D} x=\mathrm{L} / 15$ and $\mathrm{D} z=B_{\mathrm{w}} / 7$.

Substituting equations (8) to (10) into equation (1) gives

$$
\begin{aligned}
& -\left(h_{i+0.5, j}^{3}+h_{i-0.5, j}^{3}+h_{i, j+0.5}^{3}+h_{i, j-0.5}^{3}\right) p_{i, j} \\
& +h_{i+0.5, j}^{3} p_{i+1, j}+h_{i-0.5, j}^{3} p_{i-1, j}+h_{i, j+0.5}^{3} p_{i, j+1} \\
& \quad+h_{i j-0.5}^{3} p_{i, j-1}=12 \mu \mathrm{D} x^{2} \mathrm{D} z^{2} V \\
& -6 \mu \mathrm{Dx} \mathrm{D} z^{2}\left(h_{i+0.5, j}-h_{i-0.5, j}\right) U
\end{aligned}
$$

where $i=1, \ldots, 16$ and $j=1, \ldots, 8$.

Pressure levels at these nodes are unknown except at the boundary points, i.e. the four edges of the bearing surface where $(i=1, \ldots, 16, j=1),(i=1, \ldots, 16$, $j=8),(i=1, j=2, \ldots, 7)$ and $(i=16, j=2, \ldots, 7)$, and where the gauge pressure is zero. At the four points representing the oil supply orifices at the central grid elements $(i=8, j=4),(i=8, j=5)$, $(i=9, j=4)$, and $(i=9, j=5)$, the pressure is assumed to be equal to the engine oil supply pressure $p_{0}$. Hence, the 84 linear homogeneous equations can be developed from equation (11) at the 84 unknown pressure nodes. The equations can be written in the matrix form as

$$
[\mathbf{H}]\{\mathbf{p}\}=\{\mathbf{R}\}
$$

where elements of $[\mathbf{H}]$ represent the coefficients of the unknown pressures on the left-hand side of equation (11). $\{\mathbf{p}\}$ is the unknown pressure matrix and $\{\mathbf{R}\}$ is the matrix of constants defined on the RHS of equation (11).

If oil-film thickness variation and the instantaneous relative velocities $U$ and $V$ are known for a particular crank angle position, the instantaneous pressure distribution over the linear bearing surface can be found by solving equation (12). From the resulting pressure distribution, the key bearing characteristics can be calculated, including the load carrying capacity and the friction coefficient.

\subsection{Load carrying capacity}

The load carrying capacity of the linear bearing is obtained by integrating the linear bearing pressure distribution over the bearing surface and can be expressed as

$$
F=\sum_{i=1, j=1}^{i=7, j=15} \frac{\left(p_{i, j}+p_{i+1, j}+p_{i, j+1}+p_{i+1, j+1}\right) \mathrm{d} x \mathrm{~d} z}{4}
$$




\subsection{Friction coefficient}

The friction coefficient of the linear bearing can be calculated using the following expression [6]

$$
f_{\mathrm{c}}=\sum_{i=1, j=1}^{i=7, j=15} \frac{\begin{array}{c}
{\left[\left(\mu U / h_{i, j}\right)-\left(h_{i, j} / 4 d x\right)\left(p_{i+1, j}\right.\right.} \\
\left.\left.+p_{i+1, j+1}-p_{i, j}-p_{i, j+1}\right)\right] \mathrm{d} x \mathrm{~d} z
\end{array}}{F+\left(h_{2}-h_{1}\right) / L}
$$

To obtain specified oil-film thickness and velocities $U$ and $V$, a linear bearing test rig was designed and built. The oil-film thickness, temperature, and pressure were measured at several nodes as described in the following section.

\section{DYNAMIC ANALYSIS AND LUBRICATION MEASUREMENT USING LINEAR BEARING TEST RIG}

In order to determine the critical lubrication parameters of the linear bearing, a special-purpose linear bearing test rig was designed and built, as shown in Fig. 3.

A piezo-electric pressure transducer, four oil-film thickness sensors, and two K-type thermocouples (located as shown in Fig. 3) were used to measure oil pressure, oil-film thickness, and oil temperature between the linear bearing surfaces.

Figure 3 shows the resolution of motion and forces of the linear bearing in this rig. The displacement of the centre of gravity of the con-rod assembly in

(a)

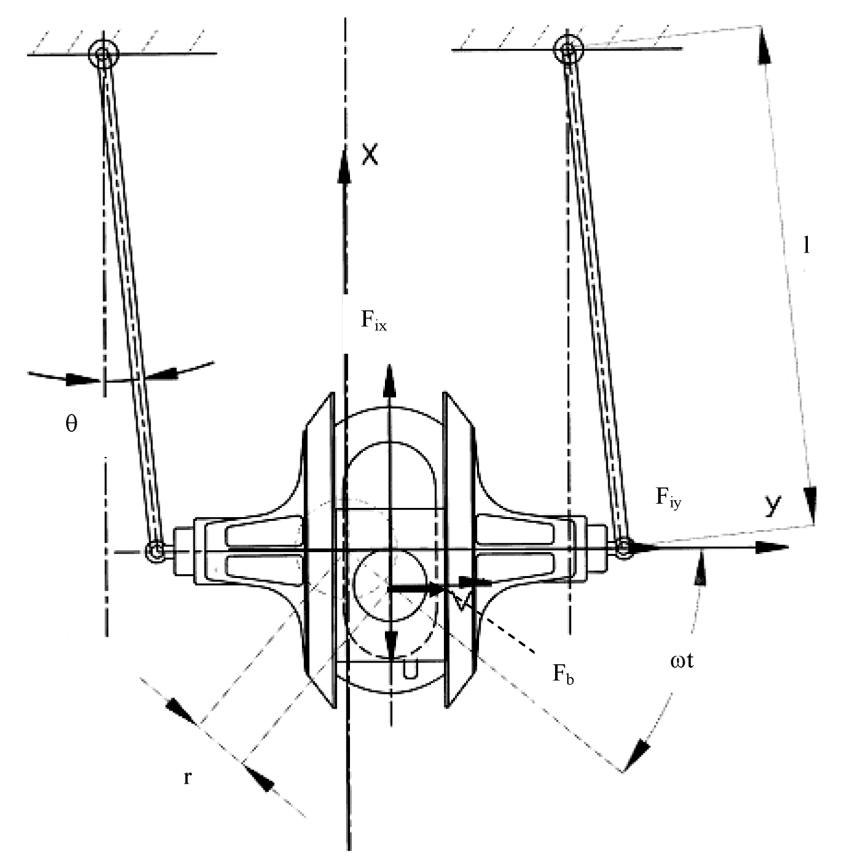

(b)

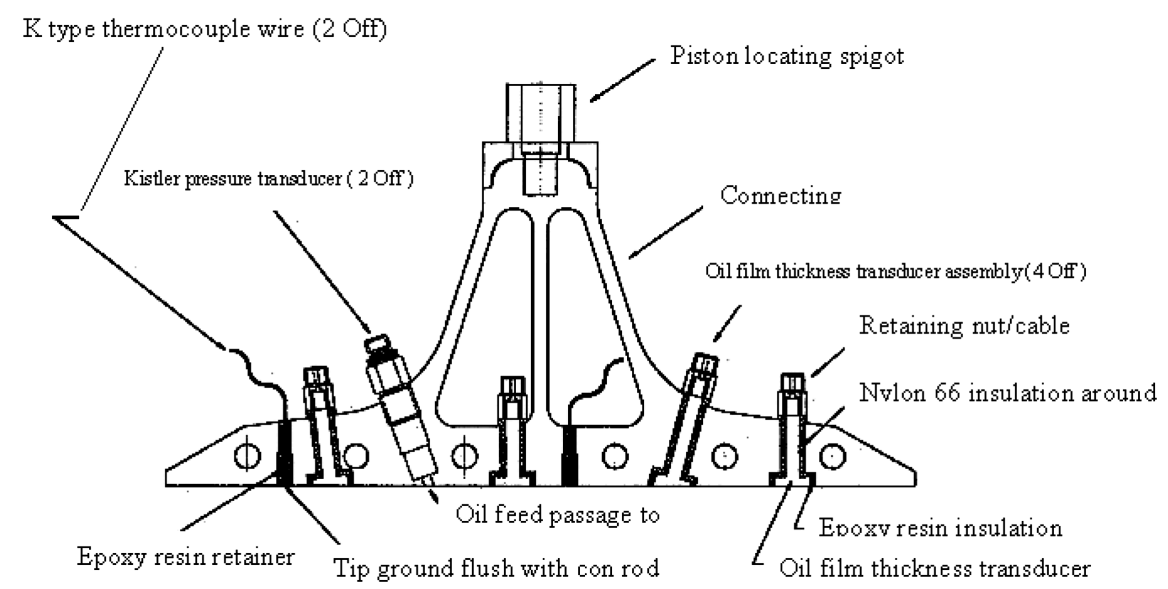

Fig. 3 Force and motion resolution for the linear bearing test rig and the cross-section through connecting rod, showing transducer locations and installation details [7] 
the $x$ - and $y$-directions at one instantaneous crank angle position $\omega t$ is expressed as

$$
\begin{aligned}
& y_{\mathrm{c}}=l \sin \theta \\
& x_{\mathrm{c}}=l-l \cos \theta
\end{aligned}
$$

where $l$ is the support arm length, $\omega$ the angular velocity of the crankshaft, $t$ the time, and $\theta$ the angle of the sway arm with respect to the vertical axis $x$ at the crank angle position $\omega t$. The crankshaft rotates in the clockwise direction and a zero crank angle is defined by the horizontal $y$-axis.

The displacement of the centre of gravity of the linear bearing block in the $x$ - and $y$-directions can be written as

$$
\begin{aligned}
& y_{\mathrm{b}}=r \sin \left(\omega t+\frac{\pi}{2}\right) \\
& x_{\mathrm{b}}=-r+r \cos \left(\omega t+\frac{\pi}{2}\right)
\end{aligned}
$$

where $r$ is the crank throw radius and $y_{\mathrm{c}}$ is assumed to be equal to $y_{\mathrm{b}}$, which leads to

$$
\begin{aligned}
& \sin \theta=\frac{r}{l} \sin \left(\omega t+\frac{\pi}{2}\right) \\
& \cos \theta=\sqrt{1-\left(\frac{r}{l}\right)^{2} \cos ^{2} \omega t} \\
& \dot{\theta}=\frac{r \omega}{l} \frac{\sin \omega t}{\cos \theta} \\
& \ddot{\theta}=\dot{\theta}^{2} \frac{\sin \theta}{\cos \theta}-\frac{r \omega^{2}}{l} \frac{\cos \omega t}{\cos \theta}
\end{aligned}
$$

The sliding velocity of the linear bearing block with respect to the connecting-rod surface can be written as

$$
U=-r \omega \sin \left(\omega t+\frac{\pi}{2}\right)-l \dot{\theta} \sin \theta
$$

The inertia forces of the connecting-rod assembly in the $x$ - and $y$-directions can be written as

$$
F_{i x}=M_{\mathrm{c}} l\left(\ddot{\theta} \sin \theta+\dot{\theta}^{2} \cos \theta\right)
$$

and

$$
F_{i y}=M_{\mathrm{c}} l\left(\ddot{\theta} \cos \theta-\dot{\theta}^{2} \sin \theta\right)
$$

where $M_{\mathrm{c}}$ is the mass of the connecting-rod assembly. When the support arm length $l$ becomes very large, as shown in Fig. 3, the linear bearing reaction force in $y$-direction $F_{\mathrm{b}}$ can be written as

$$
F_{\mathrm{b}} \approx-F_{i y}=-M_{\mathrm{c}} r \omega^{2} \cos \omega t
$$

The inertia force of the connecting-rod assembly in the $x$-direction $F_{i x}$ tends to zero.

Figure 1 shows the Scotch Yoke connecting rod and the linear bearing in a sectional view where the forces acting on the connecting rod and the bearing block are given. The linear bearing reaction force in a firing Scotch Yoke engine can be written as

$$
F_{\mathrm{b}}=\left[P_{1}(\omega t)-P_{2}(\omega t)\right] \frac{\pi D^{2}}{4}-M_{\mathrm{c}} r \omega^{2} \cos \omega t
$$

where $P_{1}(\omega t)$ and $P_{2}(\omega t)$ are the combustion pressures in the two opposite cylinders acting on the two piston crowns and $D$ is the cylinder bore. The crankpin reaction force $T$ in both the linear bearing test rig and the firing Scotch Yoke engine can be written as

$$
\begin{aligned}
& T=\sqrt{F_{\mathrm{b}}^{2}+M_{\mathrm{b}}^{2} r^{2} \omega^{4}-2 F_{\mathrm{b}} M_{\mathrm{b}} r \omega^{2} \cos \omega t} \\
& \theta_{\mathrm{l}}=\tan ^{-1} \frac{-M_{\mathrm{b}} r \omega^{2} \sin \omega t}{F_{\mathrm{b}}-M_{\mathrm{b}} r \omega^{2} \cos \omega t}
\end{aligned}
$$

where $M_{\mathrm{b}}$ is the mass of the linear bearing block and $\theta_{1}$ is the crankpin reaction force vector angle with respect to the $y$-axis. The linear bearing reaction force and the crankpin reaction force in the CMC 422 Scotch Yoke engine can be calculated by using equations (25) to (27). The linear bearing reaction force is plotted in Fig. 4.

The solid line curve in Fig. 4 shows the linear bearing reaction at a low speed of $1500 \mathrm{r} / \mathrm{min}$, and the dashed line curve in Fig. 4 shows the bearing reaction force at a high speed of $5500 \mathrm{r} / \mathrm{min}$. It can be seen from Fig. 4 that the combustion pressure effects near $360^{\circ}$ and $540^{\circ}$ crank angle positions are large at a low engine speed of $1500 \mathrm{r} / \mathrm{min}$. The inertia force effects at $180^{\circ}$ and $720^{\circ}$ crank angle positions are large at a high engine speed of $5500 \mathrm{r} / \mathrm{min}$, as confirmed in reference [4]. The dotted square wave curves in Fig. 4 show the oil supply timing of the present Scotch Yoke engine linear bearing. Figure 4 indicates that at a low speed of $1500 \mathrm{r} / \mathrm{min}$ and at $360^{\circ}$ and $540^{\circ}$ crank angles corresponding to the top dead centre (TDC) positions of the combustion strokes, the linear bearing reaction force is a maximum. At those points, the square wave value is unity, indicating that the oil supply ports in the bearing plates open, and that lubricating oil is supplied from the crankpin ports to the oil passages of the bearing block through the leading and trailing ports of the journal bearing shell, as shown in Figs 1 and 4 . 


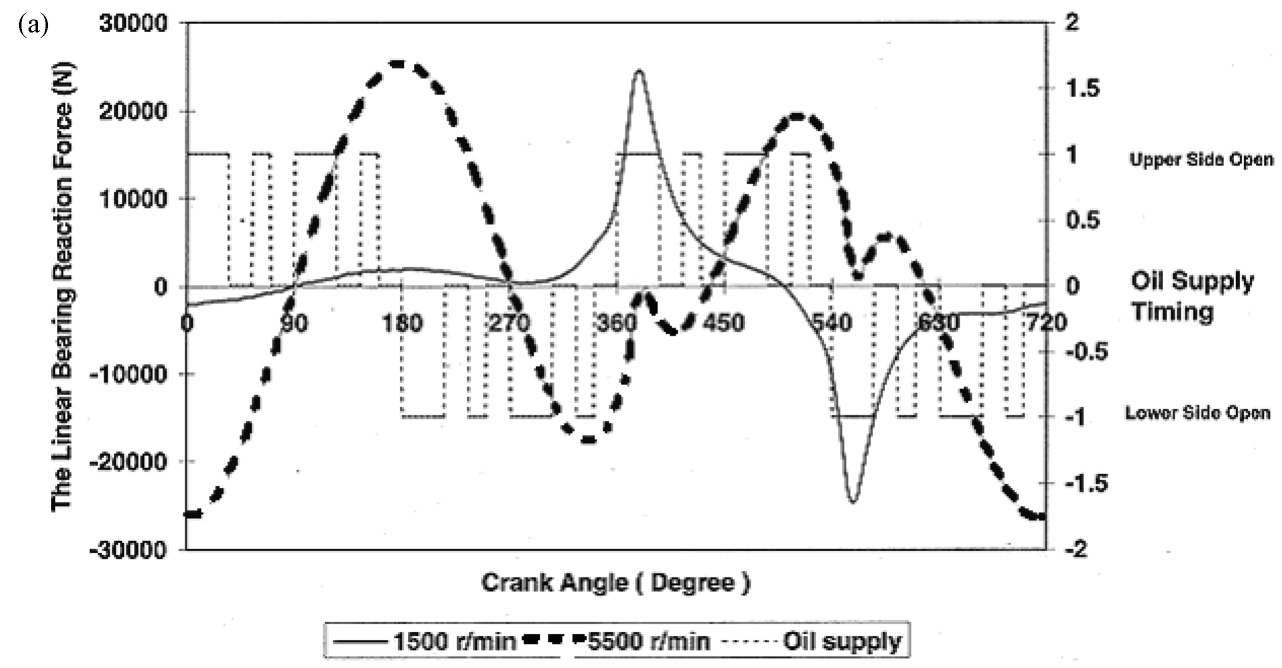

(b)

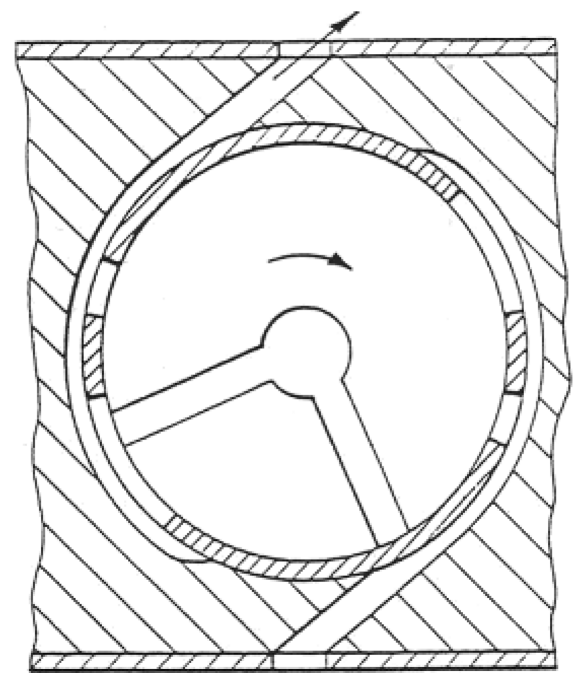

Fig. 4 Linear bearing reaction force for the CMC 422 Scotch Yoke engine at 1500 and $5500 \mathrm{r} / \mathrm{min}$ and a sectional view of the linear bearing and crankpin configuration

This indicates that at a low engine speed, the engine oil supply pressure has an important effect on the linear bearing load capacity. At a high engine speed and at $180^{\circ}$ and $720^{\circ}$ crank angles corresponding to the bottom dead centre and TDC of the induction stroke, the linear bearing reaction force is maximum. At those points, the square wave values are not unity, indicating that at the crank angles, the oil supply to the linear bearings is isolated from the engine oil supply, and that the linear bearing load capacity depends upon the squeezing hydrodynamic action of the residual oil between the linear bearing surfaces.

Comparison of equation (24) with equation (25) indicates that the linear bearing test rig with very long support arms is able to model the lubrication of the linear bearing in the firing Scotch Yoke engine at no load, where the combustion pressures $P_{1}(\omega t)$ and $P_{2}(\omega t)$ are relatively small. The first term $\left(P_{1}-P_{2}\right) \pi D^{2} / 4$ can be ignored in comparison with the second term in equation (25), which makes equation (25) identical to equation (24). The lubrication mechanism of the linear bearing in the test rig tends to be same as that in the firing CMC Scotch Yoke engine at zero load, which is the most critical condition for the linear bearing, as illustrated in reference [7].

By the substitution of equation (21) into equation (11) or (12), the coefficient array $\{\mathrm{R}\}$ on the RHS of equation (11) can be determined, except that the bearing squeezing speed $V$ is unknown. In order to determine the bearing squeezing speed $V$, it is 
assumed that the linear bearing reaction force acting upon the bearing block is equal to the bearing load capacity at any crank angle position. By assigning any initial value to the bearing squeezing speed $V$, equation (11) can be solved at a specified crank angle position and the pressure distribution over the bearing surface can be found; and by integrating the pressure distribution over the bearing surface, the bearing load capacity can be determined. Iteration can be performed until the bearing load capacity is equal to the linear bearing reaction force at this crank angle position. The bearing squeezing speed $V$ and the pressure distribution after iteration can be used to calculate the linear bearing performance characteristics and are compared with the experimental results as follows.

\section{TWO-DIMENSIONAL LUBRICATION FLOW SIMULATION RESULTS}

A MATLAB program is used to solve equation (11) and to conduct the required numerical iteration. Table 1 lists the input parameters for this program, which include the measured parameters from the test rig, namely, the oil supply pressures at the inlet port of the linear bearing and the oil-film thicknesses at the leading and trailing edges at different rotational speeds and crank angles.

From the numerical simulation, the linear bearing oil-film pressure distributions have been obtained.

Figures 5 and 6 show the linear bearing pressure distributions at the crank angle position of $260^{\circ}$ for the rotational speeds of 1000 and $1500 \mathrm{r} / \mathrm{min}$. Figure 7 shows the bearing oil-film pressure distribution at the crank angle position of $230^{\circ}$ for the rotational speed of $1500 \mathrm{r} / \mathrm{min}$.

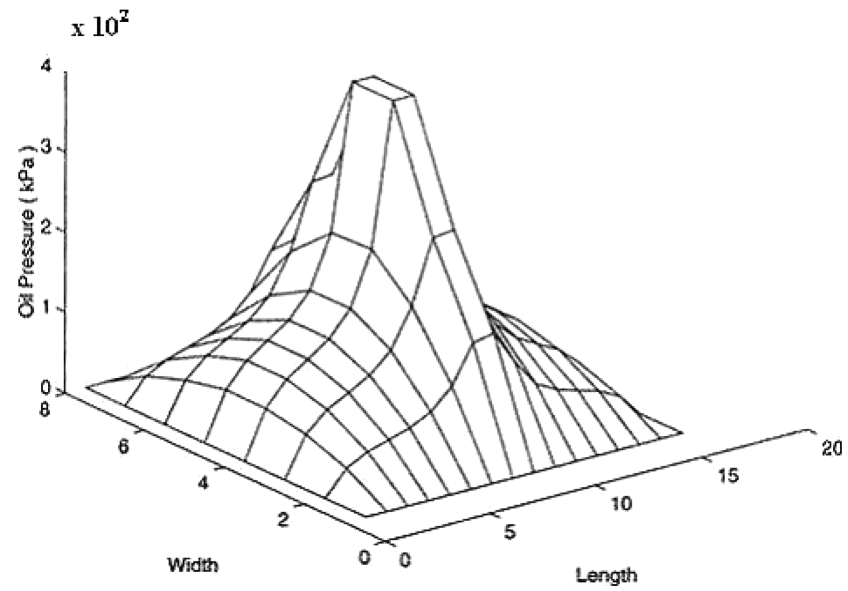

Fig. 5 Oil-film pressure distribution of the linear bearing at $1000 \mathrm{r} / \mathrm{min} 260^{\circ}$ crank angle position

From Figs 5 and 6, it can be seen that the volume under the oil pressure distribution profile increases as the rotational speed increases, indicating that the linear bearing load capacity increases as the rotational speed increases. It can be seen here that the oil-film pressure distributions are symmetrical about the centre plane of the bearing width and asymmetrical about the centre plane of the bearing length. The integration of the oil-film pressure distribution over the bearing surface gives the bearing load capacity.

As the rotational speed increases, the bearing load capacity increases, enabling the maintenance of normal bearing lubrication with the increased bearing reaction force. As the rotational speed increases, the connecting-rod assembly reciprocating inertia force and the bearing reaction force increase.

At low rotational speeds, the oil-film pressure distributions only have a single peak, whereas at high

Table 1 Input parameters for the simulation program

\begin{tabular}{|c|c|c|c|}
\hline Parameter names & \multicolumn{2}{|c|}{ Symbols and numbers } & Unit \\
\hline Crank throw & \multicolumn{2}{|c|}{$r=0.0375$} & $\mathrm{~m}$ \\
\hline Connecting rod-C-plates reciprocating mass & \multicolumn{2}{|c|}{$M_{\mathrm{c}}=2.37$} & $\mathrm{~kg}$ \\
\hline Mass of the linear bearing & \multicolumn{2}{|c|}{$M_{\mathrm{b}}=0.5465$} & $\mathrm{~kg}$ \\
\hline The linear bearing test rig sway arm length & \multicolumn{2}{|c|}{$l=0.445$} & $\mathrm{~m}$ \\
\hline The linear bearing length & \multicolumn{2}{|c|}{$L=0.082$} & $\mathrm{~m}$ \\
\hline The linear bearing width & \multicolumn{2}{|c|}{$B_{\mathrm{w}}=0.021$} & $\mathrm{~m}$ \\
\hline Mesh number in the bearing length direction & \multicolumn{2}{|c|}{$n_{x}=15$} & \\
\hline Mesh number in the bearing width direction & \multicolumn{2}{|c|}{$n_{z}=7$} & \\
\hline \multicolumn{4}{|l|}{$260^{\circ}$ crank angle position } \\
\hline Crank rotational speed (r/min) & 500 & 1000 & 1500 \\
\hline Measured oil supply pressure (kPa) & 300 & 400 & 500 \\
\hline Measured oil-film thickness at the trailing edge $(\mu \mathrm{m})$ & 27.58 & 33.17 & 18.57 \\
\hline Measured oil-film thickness at the leading edge $(\mu \mathrm{m})$ & 46.9 & 29.83 & 24.04 \\
\hline \multicolumn{4}{|l|}{$230^{\circ}$ crank angle position } \\
\hline Crank rotational speed (r/min) & & 500 & 1500 \\
\hline Measured oil supply pressure (kPa) & & 300 & 500 \\
\hline Measured oil-film thickness at the trailing edge $(\mu \mathrm{m})$ & & 21.94 & 25.17 \\
\hline Measured oil-film thickness at the leading edge $(\mu \mathrm{m})$ & & 45.62 & 18.52 \\
\hline
\end{tabular}




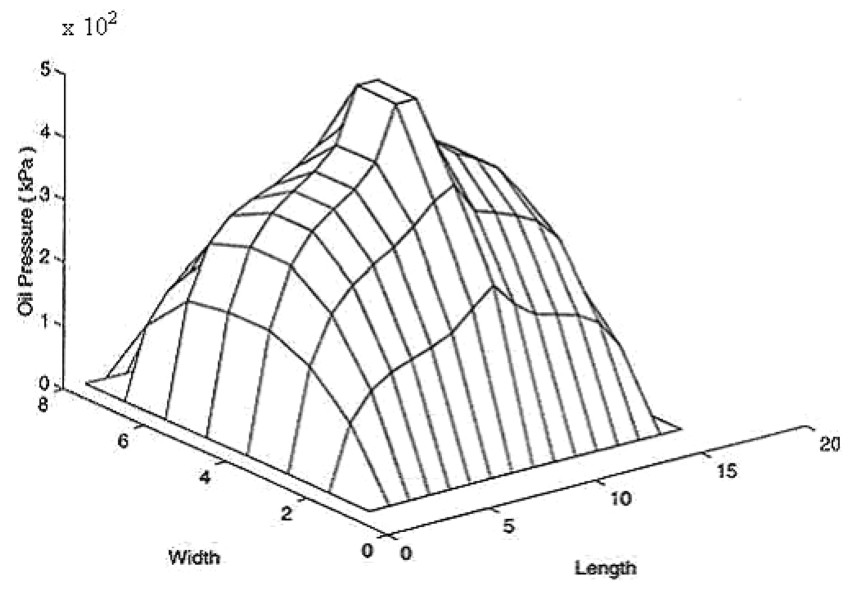

Fig. 6 Oil-film pressure distribution of the linear bearing at $1500 \mathrm{r} / \mathrm{min} 260^{\circ}$ crank angle position

speeds, the oil-film pressure distributions have two peaks, as shown in Fig. 7. As the rotational speed increases, the maximum oil-film pressure increases. The single peak distribution means that the oil tends to come out of the supply ports and to spread outwards. The twin peak distribution means that some oil in-between the bearing surfaces tends to flow back to or be sucked back to the supply ports. The phenomenon of the bearing oil flowing into or out of the supply ports at different crank angle positions characterizes the linear bearing lubrication at high speeds. The number of the peaks also depends on the crank angle position.

At low rotational speeds and for a single peak oilfilm pressure distribution, the sliding effect is greater than the squeezing effect; at high speeds and in a twin-peak oil-film pressure distribution, the squeezing effect is greater than the sliding effect. This is because the sliding speed increases linearly with the rotational speed, as per equation (21), whereas

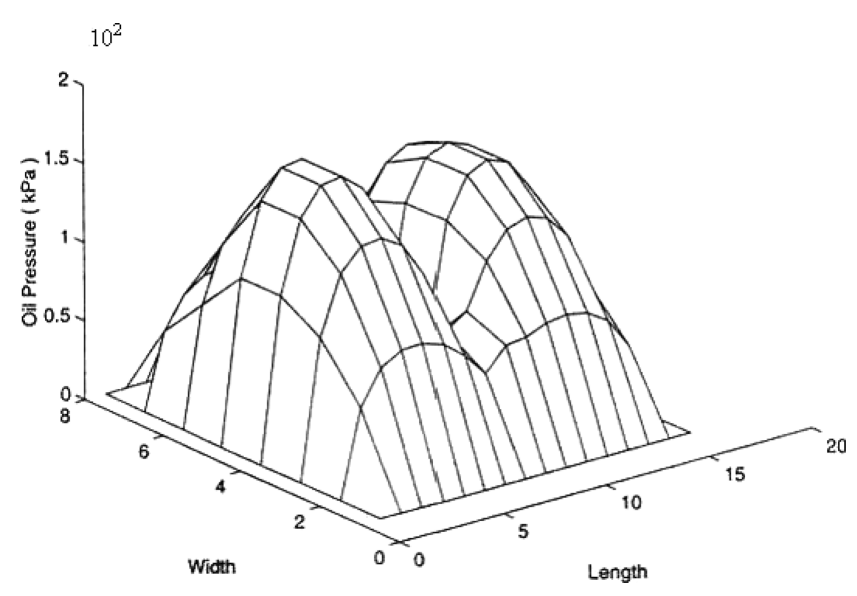

Fig. 7 Oil-film pressure distribution of the linear bearing at $1500 \mathrm{r} / \mathrm{min} 230^{\circ}$ crank angle position the squeezing speed increases linearly with the inertia force of the con-rod assembly, which is proportional to the square of the rotational speed, as per equation (24). The squeezing speed increases much faster than the sliding speed at high rotational speeds. When the bearing oil supply opens through the crankpin channel, the oil supply pressure has a larger influence on the bearing load capacity at low-rotational speeds than at high-rotational speeds. At high rotational speeds, the large squeezing effect produces enough load capacity and maintains hydrodynamic lubrication of the bearing.

When the bearing oil supply is cut off from the crankpin oil channel, the residual oil between the linear bearing surfaces is squeezed and the oil-film becomes thinner, which provides sufficient load capacity. This is because the oil pressure from the squeezing effect is inversely proportional to the cube of the oil-film thickness, whereas the oil pressure from the sliding effect is inversely proportional to the oil-film thickness, as per equations (4) and (7).

Table 2 lists the measured and predicted oil-film pressures for the test rig at different conditions using the MATLAB program. From the calculated oil-film pressure distributions, the pressures at two specific points are obtained (Table 2). One of the points was $55 \mathrm{~mm}$ away from the leading edge and in the centre plane of the bearing width, and the other point was also in the centre plane of the bearing width and $46.8 \mathrm{~mm}$ away from the leading edge. Figure 3 shows the pressure sensors inserted through the con-rod, which measured oil-film pressures at the two specific points. The predicted results coincided with the measured results except for the case of $1500 \mathrm{r} / \mathrm{min}$, at the position of $230^{\circ}$ crank angle, as shown, in Fig. 7. According to the measured data in this case in Table 2, the oil supply port pressure at the centre hole of the linear bearing surface was $500 \mathrm{kPa}$, and the measured oil-film pressure at the point $46.8 \mathrm{~mm}$ away from the leading edge was $386 \mathrm{kPa}$.

If the oil pressure distribution had a single peak at the centre of the bearing surface as indicated by the measured pressure data, the bearing load capacity obtained by integrating the oil pressure distribution over the bearing surface would be less than the product of the pressure peak value and the linear bearing surface area, which equals $861 \mathrm{~N}$. The linear bearing reaction force in this case was $1409 \mathrm{~N}$ according to equation (24), which means that the bearing load capacity was smaller than the bearing side force. If that had occurred, hydrodynamic lubrication could not be maintained, the oil-film could break down, and there could be contacts between metal surfaces in the bearing. In practice, the linear bearing surface did not have any signs of scratches or damage, suggesting that the oil-film pressure distribution 
Table 2 Measured and predicted oil-film pressures for the linear bearing test rig at different conditions

Oil film pressure at the position of $55 \mathrm{~mm}$ from the bearing leading edge at $260^{\circ}$ crank angle position $\begin{array}{llll}\text { Crank rotational speed (r/min) } & 500 & 1000 & 1500\end{array}$

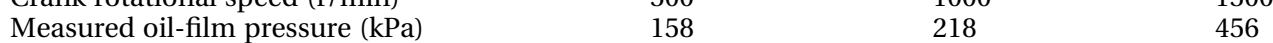

$\begin{array}{llll}\text { Calculated oil-film pressure }(\mathrm{kPa}) & 118.7 & 218.8 & 422.5\end{array}$

Oil-film pressure at the position of $46.8 \mathrm{~mm}$ from the bearing leading edge at $230^{\circ}$ crank angle position

Crank rotational speed (r/min)

Measured oil-film pressure $(\mathrm{kPa})$

Calculated oil-film pressure $(\mathrm{kPa})$

$\begin{array}{ll}500 & 1500 \\ 168 & 386 \\ 194.6 & 1275.5\end{array}$

was not a single peak pressure distribution. The measured pressure in this case must be incorrect. This might be caused by the effect of measurement noise on the measured signals. Only the twin peak oil pressure distribution as in Fig. 7 would make it possible for the linear bearing load capacity to equal the linear bearing reaction force.

\section{LINEAR BEARING PERFORMANCE CHARACTERISTICS AND GEOMETRY DESIGN OPTIMIZATION}

From the two-dimensional lubricant flow modelling, some of the linear bearing performance characteristics can be obtained. Figures 8 and 9 predict the relationships of bearing load capacity and friction coefficient with the bearing length and width. These results were obtained at the rotational speed of $1000 \mathrm{r} / \mathrm{min}$, at $260^{\circ}$ crank angle under the assumption that the bearing oil-film thickness, oil-film shape, and the oil-film squeezing speed were stable and reproducible. The bearing performance parameters were calculated from equations (13) and (14).
From Fig. 8, it can be seen that when the linear bearing length is kept constant and the bearing width increases, the bearing surface area, the bearing load capacity, and the friction coefficient increases. For example, doubling the width from 20 to $40 \mathrm{~mm}$ increases the load capacity by a factor of four. This result is different from the conclusion from equation (5), which indicates that the load capacity is proportional to the cube of the bearing width. This is because equation (5) is a one-dimensional solution of the Reynolds equation, which assumes that the sliding speed $U=0$ and that there is constant pressure distribution along the length of the linear bearing. The onedimensional solution overestimates the effect of the bearing width on the load capacity. In other words, the pressure variation along the bearing length and the sliding speed may play a role in reducing the effect of the bearing width on the load capacity.

Corresponding to this $2 \times$ increase in the bearing width is an increase in friction coefficient by about $2 \times$ as well. It can be seen from Fig. 9 that when the linear bearing width is kept constant and the bearing length increases, the bearing load capacity and the friction coefficient increase. In general, it can be

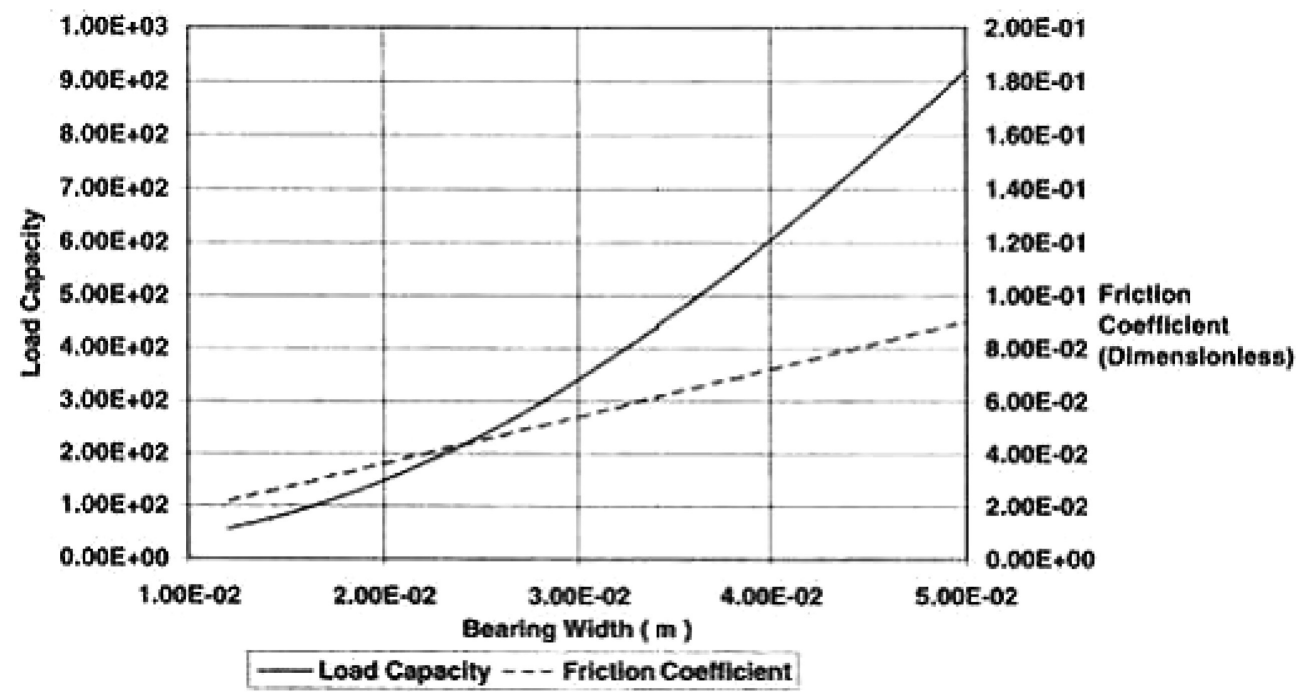

Fig. 8 Relationships of the load capacity and the friction coefficient with the bearing width for the linear bearing at $1000 \mathrm{r} / \mathrm{min} 260^{\circ}$ crank angle 


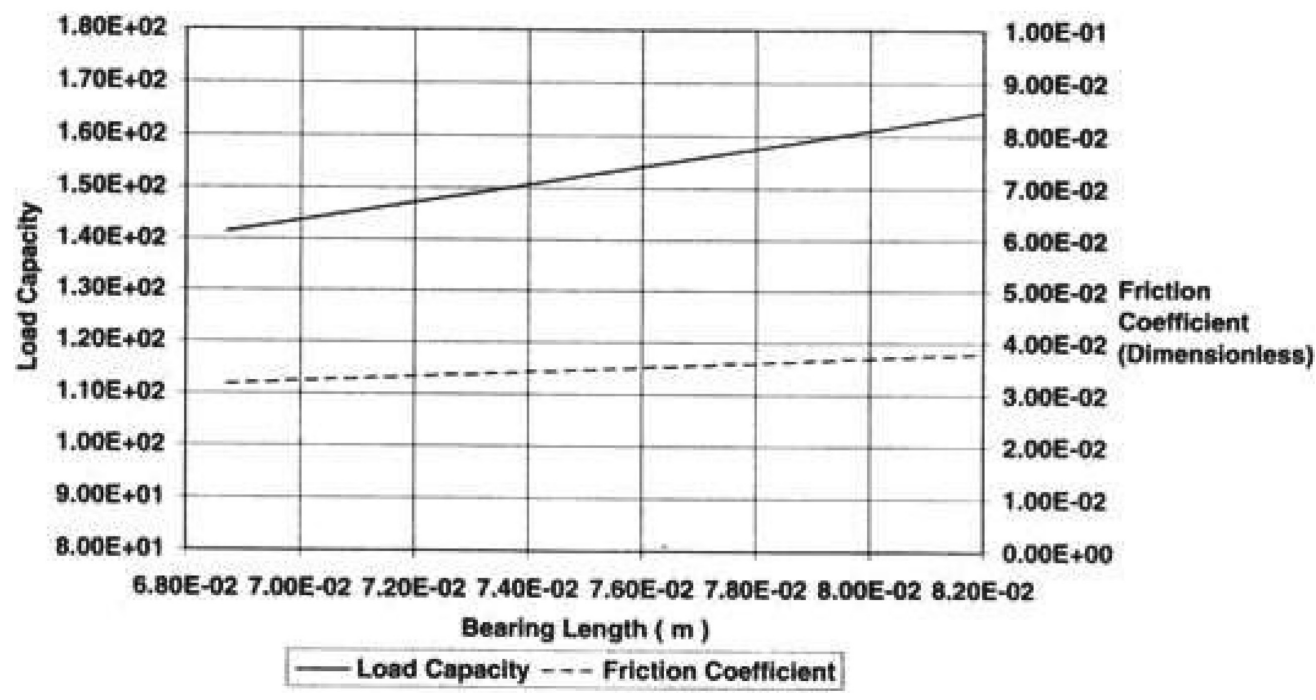

Fig. 9 Relationships of the load capacity and the friction coefficient with the bearing length for the linear bearing at $1000 \mathrm{r} / \mathrm{min} 260^{\circ}$ crank angle

concluded that these parameters are much more sensitive to the changes in width than to the changes in length.

The preceding geometry sensitivity analysis indicates that the dimensional changes of the bearing should be made to achieve sufficient load capacity with the minimum bearing surface area or the minimum friction coefficient. As the width change is restricted by the connecting-rod design, only bearing length change is possible. If the bearing length reduces from 0.082 to $0.068 \mathrm{~m}$ and the squeezing speed was not changed, the instantaneous oil-film thickness would have to be reduced to maintain the bearing load capacity at a specific rotational speed.
Figure 10 shows the bearing load capacities at 1000 and $1500 \mathrm{r} / \mathrm{min}$, which are equal to the applied reaction forces on the bearing block at the two rotational speeds. As the bearing length increases, the bearing load capacity increases. The friction coefficients at the two speeds decrease as the bearing length decreases. In a new design version of the CMC 422 Scotch Yoke engine, the linear bearing length was reduced from 0.082 to $0.07 \mathrm{~m}$; it was shown to work well as the engine friction was reduced. It should be noted that the reduction of the linear bearing length was also restricted by the dimensions of the crank pin and the bearing connecting bolts.

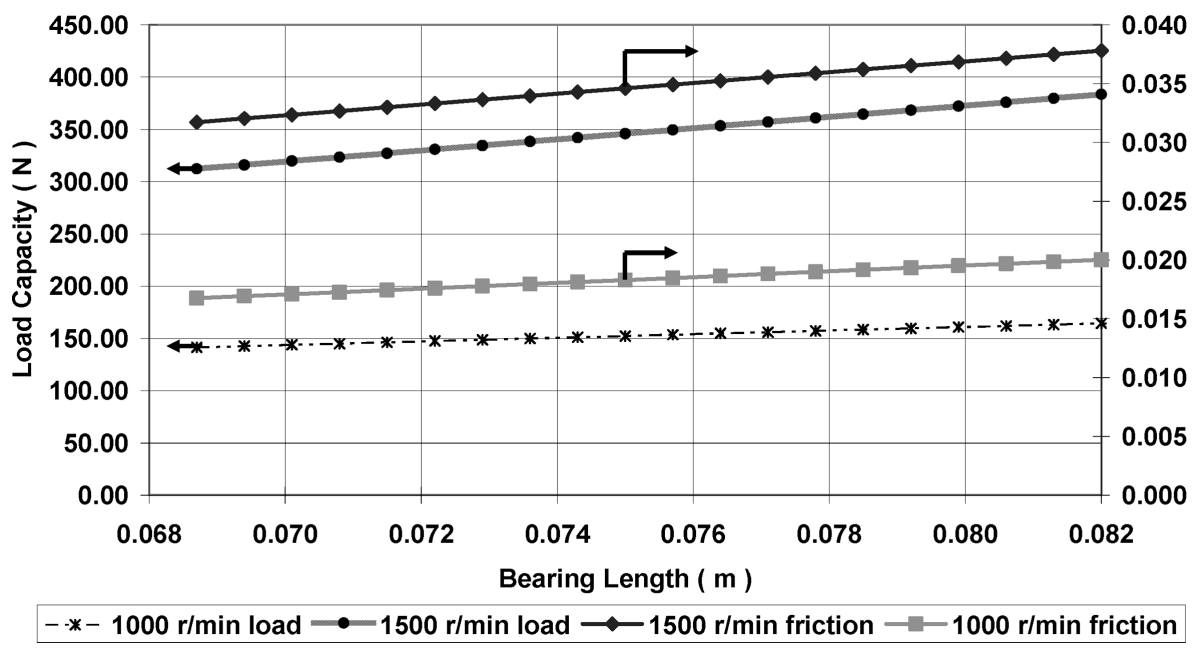

Fig. 10 Bearing load capacities and the bearing friction coefficient versus the bearing length at 1000 and $1500 \mathrm{r} / \mathrm{min}$ where the bearing load capacities were enough 


\section{CONCLUSIONS}

A numerical model of a two-dimensional lubrication flow has been developed and used to simulate lubrication of the linear bearing of a Scotch Yoke engine. The results of the simulation were compared with experimental results obtained using a custom-built bearing test rig. The following conclusions have been drawn.

1. Dynamic analyses for the linear bearing test rig and the linear bearing assembly of the Scotch Yoke engine showed that the test rig satisfactorily simulated the lubrication mechanism for the Scotch Yoke engine at a no-load condition.

2. The bearing load capacity associated with the squeezing effect of the lubricant film increases with the squeezing speed and the bearing width. The bearing oil-film pressure associated with the sliding effect of the film increases with the sliding speed and the bearing length.

3. The bearing oil-film pressure and the load capacity are inversely proportional to the cube of the oil-film thickness for the squeezing effect and are inversely proportional to the oil-film thickness for the sliding effect. The oil-film thickness depends on the bearing clearance.

4. The bearing oil supply timing also has an important effect on the linear bearing lubrication. When the linear bearing oil supply ports are open and connected to the engine oil supply, the oil supply pressure will contribute to the bearing oil-film pressure and the load capacity. When the bearing oil supply ports are cut off away from the engine oil supply, the residual oil between the bearing surfaces will be squeezed and the oil-film thickness will be reduced, providing the required bearing load capacity. The oilfilm pressure distribution may have either a single or twin peaks.

5. As the bearing width or length increases, its load capacity and friction coefficient increase. The latter are much more sensitive to change of the bearing width than to change of the bearing length.

6. The optimization strategy for the Scotch Yoke engine will be the minimization of the bearing surface area and the bearing friction coefficient while maintaining sufficient bearing load capacity.

\section{ACKNOWLEDGEMENTS}

This authors would like to express their thanks to Richard Gabler for providing experimental results, Dr Hans G. Rosenkranz for his advice and support.

\section{REFERENCES}

1 Aitken, A., Daniel, M., and Fountain, G. The CMC Scotch Yoke engine - a family of engines for automotive use. SAE paper no. 901532, 1990.

2 Close, H., Szydlowski, W., and Downton, C. Perfect engine balance via collins Scotch Yoke technology. SAE paper no. 941039, 1994.

3 Close, H. The compact collins Scotch yoke engine more progress. SAE paper no. 930314, 1993.

4 Daniel, M. Interconnecting rotary and reciprocating motion. International Patent Classification: F01B 9/02, (WO 93/04269), 1993.

5 Fuller, D. D. Theory and practice of lubrication for engineers, 1956 (Wiley, New York).

6 Bagci, C. and Singh, A. P. Hydrodynamic lubrication of finite slider bearing: effect of one dimensional film shape, and their computer aided optimum design. J. Lubr. Technol. Trans. ASME, 1983, 105, 1-38.

7 Wang, X. Dynamic analysis of the Scotch Yoke components. CMC Research Report 94/2, The University of Melbourne, 1994.

\section{APPENDIX}

\section{Notation}

$B_{\mathrm{w}}$

$D$

$\mathrm{D}_{x}, \mathrm{D}_{y}, \mathrm{D}_{z}$

F

$f_{\mathrm{c}}$

$F_{\mathrm{b}}$

$F_{x}, F_{z}$

$F_{i x}, F_{i y}$

$F_{\mathrm{a} 1}, F_{\mathrm{a} 2}$

$h_{i, j}$

$h_{i-0.5, j}$

$h_{i+0.5, j}$

$h_{i, j-0.5}$

$h_{i, j+0.5}$

$h(x), h$

$h_{1}, h_{2}$ the width of the linear bearing

block

the cylinder bore

length increments in the

directions $x, y$, and $z$

the load capacity of the linear

bearing

the friction coefficient of the linear bearing

the linear bearing side reaction

force

the forces in the $x$ - and

$z$-directions

the inertia forces of the con-rod

assembly in the $x$ - and

$y$-directions

the side forces on the top and

bottom pistons

oil-film thickness at $\left(x_{i, j}, z_{i, j}\right)$

oil-film thickness at

$\left(x_{i, j}-\mathrm{D} x / 2, z_{i, j}\right)$

oil-film thickness at

$\left(x_{i, j}+\mathrm{D} x / 2, z_{i, j}\right)$

oil-film thickness at

$\left(x_{i, j}, z_{i, j}-\mathrm{D} z / 2\right)$

oil-film thickness at

$\left(x_{i, j}, z_{i, j}+\mathrm{D} z / 2\right)$

oil-film thickness at the

position $x$

oil-film thicknesses at the trailing and leading edges 
$[\mathbf{H}]$

$l$

$L$

$M_{\mathrm{b}}$

$M_{\mathrm{c}}$

$n_{x}, n_{z}$

\section{$p$}

$\{\mathrm{p}\}$

$p_{i, j}$

$p_{i+1, j}$

$p_{i-1, j}$

$p_{i, j-1}$

$p_{i, j+1}$

$p_{1}(\omega t), p_{2}(\omega t)$

$r$

$\{\mathrm{R}\}$

$t$

$T$

$u, v, w$
$84 \times 84$ oil-film thickness

coefficient matrix

the length of the sway arm of the

linear bearing test rig

the length of the linear bearing

block

the mass of the linear bearing

block

the mass of the connecting-rod

assembly

the mesh numbers in the $x$ - and

$z$-directions

oil pressure

$84 \times 1$ oil pressure matrix

oil pressure at $\left(x_{i, j}, z_{i, j}\right)$

oil pressure at $\left(x_{i, j}+\mathrm{D} x, z_{i, j}\right)$

oil pressure at $\left(x_{i, j}-\mathrm{D} x, z_{i, j}\right)$

oil pressure at $\left(x_{\mathrm{i}, j}, z_{i, j}-\mathrm{D} z\right)$

oil pressure at $\left(x_{i, j}, z_{i, j}+\mathrm{D} z\right)$

the combustion pressures in the

top and bottom cylinders

the crank throw radius

$84 \times 1$ matrix of constants

time

the crankpin reaction force

oil flow velocities in the directions

$x, y$, and $z$
$U, V$

$x, y, z$

$x_{\mathrm{b}}, y_{\mathrm{b}}$

$x_{\mathrm{c}}, y_{\mathrm{c}}$

$\theta$

$\dot{\theta}$

$\ddot{\theta}$

$\theta_{1}$

$\mu$

$\tau_{x}, \tau_{z}$

a

$\omega t$

$\omega$ the velocities of the linear bearing block in the directions $x$ and $y$ oil-film element coordinates the centre of gravity

displacements of the linear bearing block in the directions $x$ and $y$

the centre of gravity

displacements of the connectingrod assembly in the directions $x$ and $y$

the angle of the sway arm of the linear bearing test rig the angular velocity of the sway arm of the linear bearing test rig the angular acceleration of the sway arm of the linear bearing test rig

the crankpin reaction force vector angle with respect to the $y$-axis dynamic viscosity the shear stresses producing forces in the directions $x$ and $z$ partial differentiation crank angle crankshaft rotational speed 